\title{
Study of Electrochemical and Electronical Properties on the Some Schiff Base Ni Complexes in DMSO Solvent by Computational Methods
}

Mohammad Hossein Fekria,*, Azadeh Omrani ${ }^{\mathrm{b}}$, Saeed Jameh bozorgic ${ }^{\mathrm{c}}$, Maryam Razavi Mehra $^{\mathrm{a}}$

\section{A R T I C L E I N F O \\ K E Y W O R D S \\ Schiff base \\ Gaussian 03 \\ Electrode potential \\ Energy gap \\ Electrophilicity}

Received: 21 October 2018

Revised: 2 November 2018

Accepted: 28 November 2018

Available online: 6 January 2019

\begin{abstract}
A B S T R A C T
In this study, the quantum mechanics calculations were performed on $\mathrm{M}$ (Chel) where $\mathrm{M}=\mathrm{Ni}(\mathrm{II})$ and Chel=BAE(bis-acetylacetone ethylenedimine), $\quad \mathrm{BFE}=\quad$ bis(1,1,1-triflouroacetylacetone) ethylenedimine and BCE=bis(3chloroacetylacetone)ethylenedimine) ligands using Gaussian 03 and hartree-fock theory (HF) at B3LYP/6-311G level in the gas phase and solution phase were applied. The polarized continuum model (PCM) is used to calculate salvation energies. After optimizing, various parameters such as electrode potentials, energy gap, chemical hardness, chemical potential and electrophilicity in solvent (DMSO) have been calculated. It was found to be planar and four-coordinate. Reduction potentials toward a given $\mathrm{M}(\mathrm{II})$, according to the Schiff base ligands, were changed in the trend: $\mathrm{BAE}>\mathrm{BCE}>\mathrm{BFE}$.
\end{abstract}

\section{G R A P H I C AL ABS T RACT}

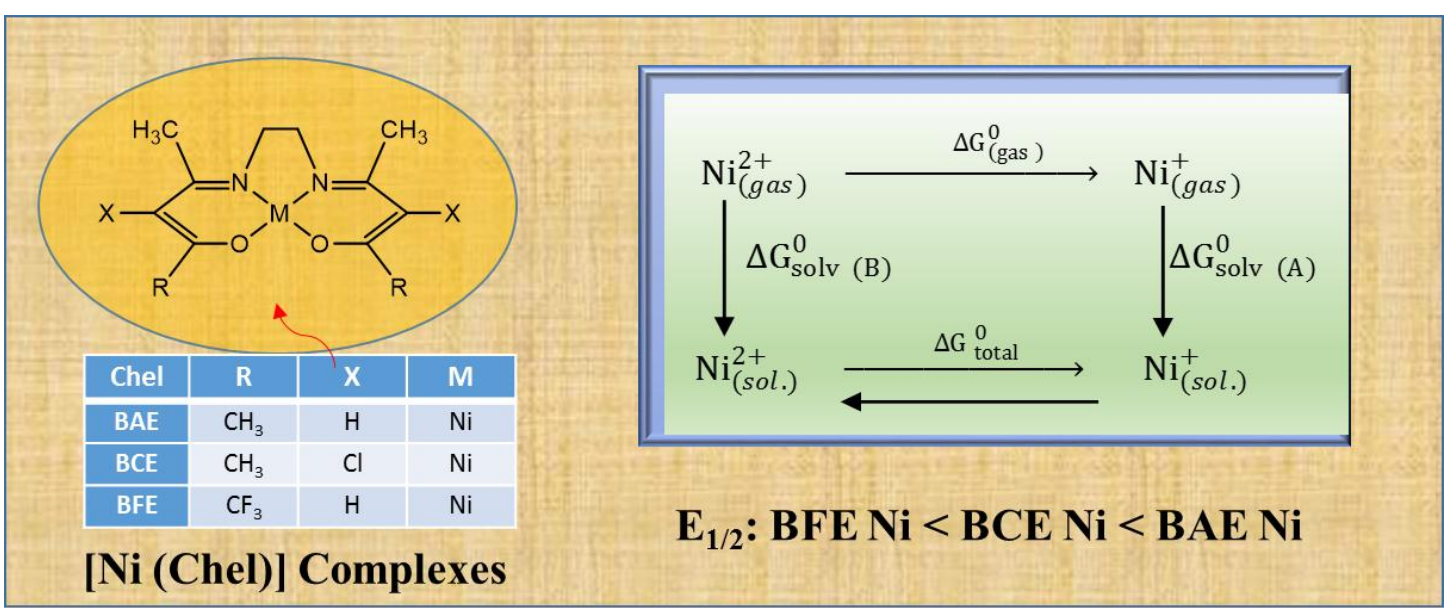

*Corresponding author's E-mail address: m.h.fekri@abru.ac.ir, Tel.: 0098-66-42509476

${ }^{a}$ Department of Chemistry, University of Ayatollah Alozma Borujerdi, Borujerd, Iran

${ }^{b}$ Department of Chemistry, Islamic Azad University, Saveh Branch, Saveh, Iran

${ }^{c}$ Department of Chemistry, Islamic Azad University, Hamedan Branch, Hamedan, Iran 


\section{Introduction}

Schiff bases are some of the most widely used organic compounds. They serve as pigments and dyes, catalysts, intermediates inorganic synthesis and polymer stabilizers [1]. Schiff bases also exhibit a wide variety of biological activities including antifungal, antibacterial, antitumor, anti-inflammatory, trypanocidal, anti-HIV, antimalarial and anti-urease activities [2-5].

Schiff bases have been widely used as ligands because of the high stability of coordination compounds with different oxidation states. The $\pi$-system in a Schiff base often imposes a geometrical constriction and affects the electronic structure as well. Transition metal Schiff base complexes have been studied as catalysts in organic redox and electrochemical reduction reactions [6]. The ability to calculate redox potentials is accurately advantageous in a number of different areas, particularly where the experimental measurement is difficult due to complex chemical equilibria and the design of molecules with particular redox properties is of interest [7].

Nickel complexes play a prominent role in bio-inorganic redox enzyme system [8] and square planar nickel complexes in context of some other factors can cause the cleavage of plasmid DNA [9].
One of the methods for studying drugs is the use of Gaussian software and hartree-fock theory (HF). The hartree-fock theory (HF) is a computational method of quantum mechanics used in physics and chemistry to examine the basic state electron structure in multiple systems, especially atoms, molecules, and dense phases. Using a series of approximations in this theory increases the accuracy of this method in the calculation of exchange-correlation interactions. The results of the HF calculations are consistent with the experimental results. This method is also close to the initial computational method and the semi-experimental computational method, because the Schrödinger equation is solved confidently and, on the other hand, the empirical data are investigated. The calculations of the functional density theory can evaluate about 500 atoms [10-12].

Thermodynamic, electron, orbital properties of drugs can be studied using Gaussian software [13]. With the help of electron properties, their reactivity can be found. Energy gap, the chemical potential $(\mu)$ chemical hardness $(\eta)$ and electrophilicity $(\omega)$ are some of the parameters that show these properties. The levels of HOMO and LUMO energies are extracted directly from the output file of Gaussian calculations [14-15].

The electrochemical properties of $\mathrm{M}(\mathrm{Chel})$ 
were observed where $\mathrm{M}=\mathrm{Ni}(\mathrm{II})$ and Chel= BAE bis(acetylacetone)ethylenediamine, $\mathrm{BFE}=$ bis(1,1,1-triflouroacetylacetone) ethylenediamine and BCE=bis(3-chloro acetylacetone ethylenediamine) ligands were investigated in DMSO as solvent. It was found to be planar and four-coordinate (Figure 1).

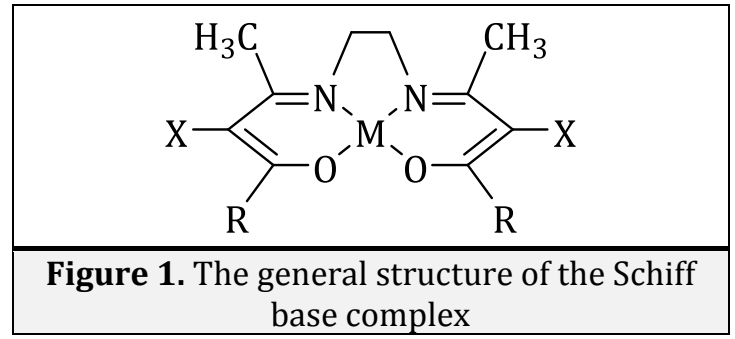

\begin{tabular}{cccc}
\hline Chel & $\mathbf{R}$ & $\mathbf{X}$ & $\mathbf{M}$ \\
\hline $\mathrm{BAE}$ & $\mathrm{CH}_{3}$ & $\mathrm{H}$ & $\mathrm{Ni}$ \\
$\mathrm{BCE}$ & $\mathrm{CH}_{3}$ & $\mathrm{Cl}$ & $\mathrm{Ni}$ \\
$\mathrm{BFE}$ & $\mathrm{CF}_{3}$ & $\mathrm{H}$ & $\mathrm{Ni}$ \\
\hline
\end{tabular}

\section{Experimental}

\section{Material and Method}

In this research, the vibrational frequencies for some complexes are calculated for validation of the structure because the molecular parameters are controlled by the structure. Moreover, standard electrode potential and other parameter of reaction for complexes is also calculated using the optimized structure at Gaussian 03 program (Figure 2). Many study results have indicated that hartee-fock theory is a powerful method for predicting the geometry and hormonic vibration of organic compounds [16-20]. Therefore, the HF/6$311 \mathrm{G}$ with polarized continuum model
(PCM) solvation containing CPCM were carried out to study the molecular structure, solvation energies, sum of electronic, thermal free energies, and the vibrational frequencies of both reduced nickel $\left(\mathrm{Ni}^{+}\right)$and their oxidized form $\left(\mathrm{Ni}^{2+}\right)$ at electrode.

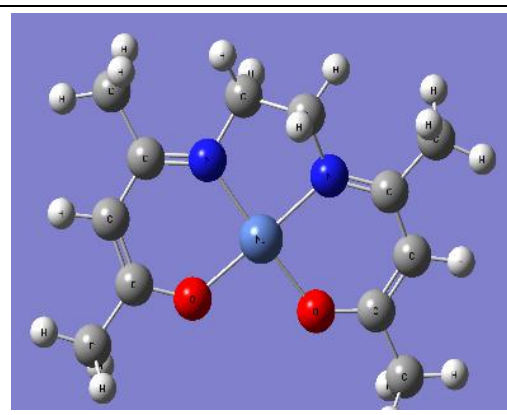

(a)

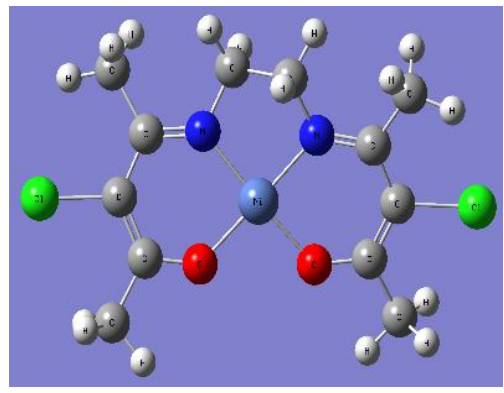

(b)

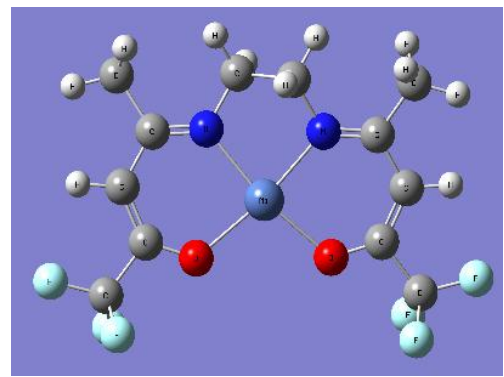

(c)

Figure 2. Optimized structure of complexes: a-Ni(BAE) b- Ni(BCE) c- Ni(BFE)

\section{Results and Discussion}

Reaction 1 depicts the one electron oxidation reaction of the $\mathrm{Ni}^{2+}$.

Reaction 1:

$\mathrm{Ni}^{2+}+\mathrm{e} \rightarrow \mathrm{Ni}^{+}$ 
Geometry optimizations for all of the compounds were performed in gas phase and solution phase on HF/6-311G level of theory. The gas-phase Gibbs free energy change $\left(\Delta \mathrm{G}_{\text {gas }}^{\circ}\right)$ of reaction 1 was calculated using Eq.1.

$$
\Delta \mathrm{G}_{\text {gas }}^{\circ}=\mathrm{G}_{\text {gas }}^{\circ}\left(\mathrm{Ni}^{+}\right)-\mathrm{G}_{\text {gas }}^{o}\left(\mathrm{Ni}^{2+}\right)
$$

A common practice to calculate Gibbs freeenergy changes of an reaction $\left(\Delta G_{\text {total }}^{\circ}\right)$ is by summing $\Delta \mathrm{G}_{\text {gas }}^{\circ}$ and $\Delta \Delta \mathrm{G}_{\text {solv }}^{\circ}$ using the thermodynamic cycle of Figure 3 and Eq. 2.

$$
\Delta \mathrm{G}_{\text {total }}^{\circ}=\Delta \mathrm{G}_{\text {gas }}^{\circ}+\Delta \Delta \mathrm{G}_{\text {solv }}^{\circ}
$$

Finaly, E ${ }_{1 / 2}^{\circ}$ is calculated according Eq. 3.

$$
\Delta \mathrm{G}_{\text {total }}^{\circ}=\mathrm{nf}\left(\mathrm{E}_{1 / 2}^{\circ}-\mathrm{E}_{\text {ref }}^{\circ}\right)
$$

$\mathrm{E}_{\text {ref }}^{\circ}$ is the experimental potential of a standard electrode (in this work reference electrode is $\mathrm{Ag} / \mathrm{AgCl}$ and $\mathrm{E}_{\text {ref. }}=0.197 \mathrm{~V}$ ), $\mathrm{E}_{1 / 2}^{\circ}$ is the calculated potential and $F$ is the faraday constant $\left(\mathrm{F}=96941 \mathrm{Cmol}^{-1}\right)$.

To obtain the half-wave potential of the drugs, first, the molecules were optimized by oxidation and reduction using Gaussian software. Then, the values of $\mathrm{G}^{0}$ were obtained for the oxidation and reduction states of the gas and solution state, besides, the values $\Delta \mathrm{G}_{\text {total }}^{0}$ were obtained for each molecule (Table 1). Finally, the half-wave potential was calculated [21] (Table 2).

Where $\Delta \mathrm{G}^{\circ}$ is total free energy for reaction 1 ,

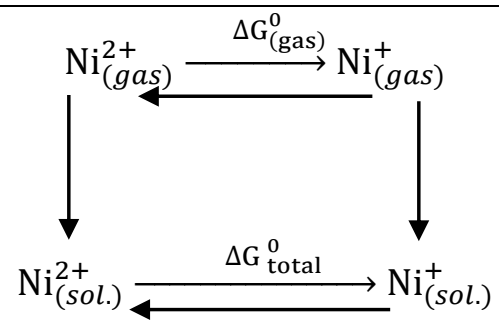

$$
\Delta \mathrm{G}_{\text {solv (B) }}^{0} \Delta \mathrm{G}_{\text {solv (A) }}^{0}
$$

\begin{tabular}{|c|c|c|c|c|}
\hline Comp. ${ }^{1}$ & $\Delta U^{0}{ }_{\text {gas }}$ & $\Delta \mathbf{G}^{\mathbf{0}}$ gas & $\Delta \Delta G^{0}{ }_{\text {solv. }}$ & $\Delta \mathbf{G}^{0}{ }_{\text {total }}$ \\
\hline $\mathrm{Ni}(\mathrm{BAE})$ & -37.75994 & -247.97845 & 38.59298 & -209.38547 \\
\hline $\mathrm{Ni}(\mathrm{BCE})$ & -266.68251 & -239.45870 & 52.94160 & -186.51710 \\
\hline $\mathrm{Ni}(\mathrm{BFE})$ & -526.87216 & -500.89809 & 367.90865 & -132.98944 \\
\hline
\end{tabular}

Figure 3. The thermodynamic cycle proposed to convert the standard Gibbs energy of an isodesmic reaction in the gas phase to the standard Gibbs energy of reaction in solution

Table 1.Thermodynamic parameters ${ }^{1}$ of the studied complexes

The energies are in $\mathrm{kjmol}^{-1}$

Table 2. Calculated standard electrode potentials of studied molecules (in V) in DMSO solvent

\begin{tabular}{ccc}
\hline & $\mathbf{E}_{\text {cal. }}$ & $\mathbf{E}_{\text {exp. }}$ \\
\hline $\mathrm{Ni}(\mathrm{BAE})$ & -1.973 & -1.901 \\
$\mathrm{Ni}(\mathrm{BCE})$ & -1.736 & -1.705 \\
$\mathrm{Ni}(\mathrm{BFE})$ & -1.181 & -1.360 \\
\hline
\end{tabular}


Reduction potentials toward a given M(II) according to the Schiff base ligands were changed in the trend: $B A E>B C E>B F E$. In contrast to the oxidation potentials, the BFE complexes with electronwithdrawing group were reduced at lower potentials. It is good agriment with experimental data [22].

The energy gap is the difference between the two energy levels of HOMO and LUMO, which is obtained as follows:

ENERGY GAP $=\mathrm{E}_{\text {LUMо }}-\mathrm{E}_{\text {Hомо }}$

$\mathrm{E}_{\text {Lumo }}$ is the lowest unoccupied level of electron and $\mathrm{E}_{\text {номо is the highest occupied }}$ level of the electron. The values of these energy levels are obtained from the NBO output file information. The higher the difference between the two energy levels of HOMO and LUMO, the harder the transfer electrons between these two levels due to the increased energy required for electron transfer between these two surfaces, and thus, reactivity decreases.

The following equation [23] calculates the amount of chemical potential:

Chemical Potential $=\frac{E_{L U M O}+E_{\text {HOMO }}}{2}$

Physically, the chemical potential $(\mu)$ describes the tendency of an electron to escape from an equilibrium system. The greater the chemical potential, the lower the stability and the greater the reactivity are meant to be. The results showed that the absolute value of chemical potential in $\mathrm{Ni}(\mathrm{BFE})$ is more than $\mathrm{Ni}(\mathrm{BAE})$ and Ni(BCE) (Table 1). In other words, $\mathrm{Ni}(\mathrm{BFE})$ is more reactive than the $\mathrm{Ni}(\mathrm{BAE})$ and $\mathrm{Ni}(\mathrm{BCE})$.

In a molecule, chemical hardness $(\eta)$ [24] measures resistance to changes in electron configuration, electron transfer or charge transfer. Based on the energy level of molecular orbitals, the chemical hardness corresponds to the mean difference between the two levels of HOMO and LUMO. The results showed that in both gas and solution phases, the chemical hardness in the Ni(BFE) was less than that of the $\mathrm{Ni}(\mathrm{BAE})$ and $\mathrm{Ni}(\mathrm{BCE})$ (Table 3).

Table 3. Calculated electronic properties of drugs: a-anthraquinone b-2,5-dimethyl-1,4benzoquinone c-phenyl-1,4-benzoquinone in three solvents $(\mathrm{eV})$

\begin{tabular}{llll}
\hline & Ni(BAE) & Ni(BCE) & Ni(BFE) \\
\hline E номо $(\mathrm{eV})$ & 0.05281 & 0.04027 & -0.17642 \\
E $_{\text {LUмо }}(\mathrm{eV})$ & 0.16273 & 0.14632 & 0.21903 \\
$\mathrm{Eg}_{\mathrm{g}}$ & 0.15088 & 0.21806 & 0.13760 \\
$\mu$ & -0.19502 & -0.14317 & 0.20669 \\
$\eta$ & 0.07540 & 0.10903 & 0.0688 \\
$\omega$ & 0.25207 & 0.09400 & 0.31047 \\
\hline
\end{tabular}


There is a direct relationship between chemical hardness and energy gap. The greater the energy gap, the harder and more stable the molecule, resulting in reduced reactivity.

In organic chemistry, an electrophile is electron absorbent. Electrophiles are either positive or neutral and have empty orbitals that are changed into rich centers to absorb electrons. When the two molecules react together, a molecule acts as a nucleophilic system (nucleophilic addition), while the other operates as an electrophilic system (electrophilic addition). Electrophilicity ( $\omega$ ) is a HOMOLUMO-dependent parameter that affects the structural reactivity. Electrophilicity is compatible with chemical potential and chemical hardness. This parameter is calculated with the following relation (Table 3) [25].

$$
\omega=\frac{\mu^{2}}{2 \eta}
$$

\section{Conclusion}

The electrochemical properties of some Schiff bases were investigated in DMSO solvent.

1. Oxidation and reduction states of molecules were optimized using Gaussian 03 software. Then, the values of $\mathrm{G}^{0}$ were obtained in gas and solution phases. Then, the values $\Delta \mathrm{G}_{\text {total }}^{0}$ were obtained for each molecule. Finally, the half-wave potential was calculated.

2. $\mathrm{E}^{0}{ }_{1 / 2}$ values for $\mathrm{Ni}(\mathrm{BAE})$ are higher than $\mathrm{Ni}(\mathrm{BCE})$ and Ni(BFE). On the other hand, any amount, oxidation potentials a molecule is lower, more easily oxidized. Consequently, its antioxidant power, is higher.

3. In conclusion, computational studies for calculation of $\mathrm{E}^{0}{ }_{1 / 2}$ were considered as very suitable to evaluate the antioxidant activity for complexes.

4. The results showed that energy gap, electrophilicity and chemical potential values of $\mathrm{Ni}(\mathrm{BFE})$ were more than $\mathrm{Ni}(\mathrm{BAE})$ and $\mathrm{Ni}(\mathrm{BCE})$. Therefore, $\mathrm{Ni}(\mathrm{BFE})$ is more reactive than $\mathrm{Ni}(\mathrm{BAE})$ and $\mathrm{Ni}(\mathrm{BCE})$.

\section{Acknowledgment}

The authors are grateful for the partial financial support from Ayatollah Ozma Borujerdi University research council via special grant.

\section{References}

[1]. L.H. Abdel-Rahman, A.M. Abu-Dief, M.S.S. Adam, S.K. Hamdan, Catal. Lett., 2016, 146, 1373-1396.

[2]. K. Sztanke, A. Maziarka, A. Osinka, M. Sztanke, Bioorgan. Med. Chem., 2013, 21, 3648-3666 .

[3]. D. Utreja, S. Singh, M. Kaur, Curr. Bioact. Compd., 2015, 11, 215-230. 
[4]. L.H. Abdel-Rahman, A.M. Abu-Dief, R.M.

El-Khatib, S.M. Abdel-Fatah, J. Photoch.

Photobio. B, 2016, 162, 298-308.

[5]. M.H. Fekri, M. Darvishpour, H. Khanmohammadi, M. Rashidipour, J. Chem. Health Risks, 2013, 3, 63-68.

[6]. D. Pletcher, H. Thompson, J. Electroanal. Chem., 1999, 464, 168-175.

[7]. A. Ghaempanah, S. Jameh-Bozorghi, M. Darvishpour, M.H. Fekri, Int. J. Electrochem. Sci., 2012, 7, 6127-6133.

[8]. A. Biswas, L.K. Das, M.G.B. Drew, G. Aromi, P. Gamez, A. Ghosh, Inorg. Chem., 2012, 51, 7993-8001.

[9]. L.N. Zhu, D.M. Kong, X.Z. Li, G. Y. Wang, Y. W. Jin, Polyhedron, 2010, 29,

[10]. G.A. Mansori, Advance in atomic \& Molecular nanotechnology, University of Illinois, 2002.

[11]. N.H. March, Electron Density Theory of atoms and molecules, Academic press, 1992.

[12]. C.A. Mebi, J. Chem. Sci., 2011, 123, 727731.

[13]. R. Ahmadi, J. Phys. Chem. Theoret. Chem., 2012, 9, 185-190.
[14]. R.G. Parr, R.G. Pearson, J. Am. Chem. Soc., 1983, 105, 7512-7516.

[15]. S. Thorsten, J. Rudolf, J, J. Mol. Model., 2000, 6, 282-288.

[16]. P. Scott, L. Radom, J. Phys. Chem., 1996, 100, 16505 .

[17]. P. Denis, O.N. Ventura, J. Mol. Struct., 2001, 537, 173 .

[18]. A.J. Abbowicz-Bienko, D.C. Bienko, Z. Latajka, J. Mol. Struct., 2000, 552, 165-175.

[19]. R. Jacob, G. Fiscker, J. Mol. Struct., 2002, 613, 175-188.

[20]. K.B. Andersen, M. Langgard, J. SpargetLarsen, J. Mol. Struct., 1999, 509, 153-163. [21] A. Ghaempanah, S. Jameh-Bozorghi, M. Darvishpour, M.H. Fekri, Int. J. Electrochem. Sci., 2012, 7, 6127.

[22]. A.H. Kianfar, S. Zargari, H.R. Khavasi, J. Iran. Chem. Soc., 2010, 7, 908-916.

[23]. M.J. Menon, Chem. Phys., 2001, 114, 7731.

[24]. R.G. Parr, L.V. Szentpaly, S. Liu, J. Am. Chem. Soc., 1999, 121, 1922-1924.

[25]. M. Rezaei Sameti, M. Rakhshi, J. Phys. Theoret. Chem., 2016, 13, 259-270.

How to cite this manuscript: Mohammad Hossein Fekri*, Azadeh Omrani, Saeed Jamehbozorgi, Maryam Razavi Mehr, Study of Electrochemical and Electronical Properties on the Some Schiff Base Ni Complexes in DMSO Solvent by Computational Methods, Adv. J. Chem. A, 2019, 2(1), 14-20. 